\title{
魚の摂餌量と増重量の関係一I. 日掑餉量が最大になる投慨回数*
}

\author{
河野秀雄・能勢幸雄 \\ (1970 年 9 月 4 日受理)
}

\begin{abstract}
Relationship between the Amount of Food Taken and Growth in Fishes-I.

Frequency of Feeding for a Maximum Daily Ration
\end{abstract}

Hideo KonO and Yukio NosE**

\begin{abstract}
When fishes are fed daily, the frequency of feeding which maximize the daily ration was examined in six species of fishes, namely, jack mackerel, Trachurus japonicus, goby, Chasmichthys gulosus, rockfish, Sebastes inermis, yakataisaki, Therapon jarbua, rainbow trout, Salmo gairdnerii irideus, and goldfish, Carassius auratus. The fishes were fed from 1 to 12 times a day for 10 days, seeing that at each feeding the fish reached satiation, and the daily rations were recorded. The results obtained are summarized as follows:

The following relationship appeared to exist between the frequency of feeding per day $(T)$ and the daily rate of feeding $(f)$;

$$
f=C\left(1-e^{-m T}\right)
$$

where $C$ is the maximum daily rate of feeding and $m$ is a constant which represents the rate of approach of the daily rate of feeding to its maximum. The value of $m$ is determined by the ratio of the satiation amount at one feeding a day to the maximum daily ration.

The daily ration seemed to be nearly maximized with 2 feedings for goby and yakataisaki, with 3 for rockfish and rainbow trout, with 4 for jack mackerel, and with 12 for goldfish (Fig. 1).
\end{abstract}

魚の摂䭒量と増重量の関係鮘の生産のしくみを明らかにする上で重要である。したがつてこれまでこ の点に関して，飼育実験の結果にもとついた多くの報告がある゙て26)。

この一連の研究では，数種の海水魚および淡水魚を飼育して，それぞれ椇飷量のできるだけ広い範囲につ いて摂能量と增重量の関係を明らかにようとした。そのためにまず，必要な二三の采件について吟味し， その条件の下で摂餌量と增重量の関係を調べた。そして, さらに，この関俰が魚の生長段階, 外的条件, あ るいは飼育期間の長さによつてどのように变化するかを明らかにしようとした。

この報告では，6種の海水魚および淡水魚について，毎日投剘する場合，1日に何回投能すれば日摂能量 が最大になるかを明らかにしよらとした。

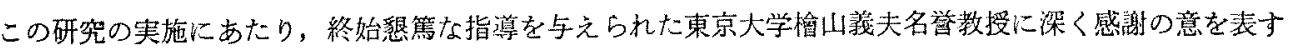
ると同時に, 有益な助言を与えられた東京大学安田富士郎博士, 清水 誠博士, 笑験に際し便宜を与えられ

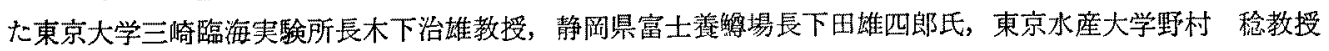

*本報告は東京大学に提出した河野秀雄の博上学位論文の一部である。

***束京大学膿学部水焦学科 (Dept. of Fisheries, Fac. of Agriculture, Tokyo Univ., Bunkyo-ku, Tokyo, Japan) 
に深く謝意を表したい。

材料と方法

投触してよく飼いならした魚群を流水（キンギョでは循環ろ過）水慒数個に20 個体（メバルでは 50 個 体）ずつ収容し，1昼夜（ニジマスでは 2 昼夜）總食させてから個体ごとに体重を測定した。翌日から水槽

Table 1. Species of fish examined, frequency and time of feeding and other experimental conditions.

\begin{tabular}{|c|c|c|c|c|c|}
\hline \multirow{2}{*}{ Species of fish } & \multirow{2}{*}{$\begin{array}{l}\text { Exp. } \\
\text { No. }\end{array}$} & \multicolumn{2}{|l|}{ Feeding } & \multirow{2}{*}{$\begin{array}{c}\text { Exp. tank } \\
\text { (length } \times \text { width } \times \text { depth, } \\
\left.\mathrm{cm}^{3}\right)\end{array}$} & \multirow{2}{*}{ Kind of food } \\
\hline & & $\begin{array}{c}\text { Frequency per } \\
\text { day }\end{array}$ & Time* & & \\
\hline Jack mackerel & $\begin{array}{l}1-1 \\
1-2 \\
1-3 \\
1-4 \\
1-5\end{array}$ & $\begin{array}{c}(1 / 5)^{* * *} \\
1 \\
3 \\
6 \\
12\end{array}$ & $\begin{array}{r}(2) \\
(5) \\
(7) \\
(9) \\
(11)\end{array}$ & $\begin{array}{r}\text { Concrete } \operatorname{tank} \\
(240 \times 128 \times 40)\end{array}$ & $\begin{array}{l}\text { Anchovy larva } \\
\text { (fresh) }\end{array}$ \\
\hline Goby & $\begin{array}{l}2-1 \\
2-2 \\
2-3 \\
2-4 \\
2-5 \\
2-6\end{array}$ & $\begin{array}{c}(1 / 5)^{* * *} \\
(1 / 2)^{* *} \\
1 \\
3 \\
6 \\
12\end{array}$ & $\begin{array}{r}(2) \\
(3) \\
(5) \\
(7) \\
(9) \\
(11)\end{array}$ & $\begin{array}{l}\text { Plastic tank } \\
(50 \times 35 \times 10)\end{array}$ & $\begin{array}{l}\text { Jack mackerel meat } \\
\text { (fresh) }\end{array}$ \\
\hline Rockfish & $\begin{array}{l}3-1 \\
3-2 \\
3-3 \\
3-4 \\
3-5\end{array}$ & $\begin{array}{c}(1 / 2) * * \\
1 \\
3 \\
5 \\
8\end{array}$ & $\begin{array}{r}(3) \\
(5) \\
(7) \\
(8) \\
(10)\end{array}$ & $\begin{array}{l}\text { Plastic tank } \\
(50 \times 35 \times 20)\end{array}$ & $\begin{array}{l}\text { Anchovy larva } \\
\text { (fresh) }\end{array}$ \\
\hline Yakataisaki & $\begin{array}{l}4-1 \\
4-2 \\
4-3 \\
4-4 \\
4-5\end{array}$ & $\begin{array}{l}1 \\
2 \\
3 \\
5 \\
8\end{array}$ & $\begin{array}{r}(5) \\
(6) \\
(7) \\
(8) \\
(10)\end{array}$ & $\begin{array}{l}\text { Plastic tank } \\
(50 \times 35 \times 10)\end{array}$ & $\begin{array}{l}\text { Marlin ovary } \\
\text { (fresh) }\end{array}$ \\
\hline Rainbow trout & $\begin{array}{l}5-1 \\
5-2 \\
5-3 \\
5-4 \\
5-5 \\
5-6 \\
5-7 \\
5-8\end{array}$ & $\begin{array}{c}(1 / 10)^{* *} \\
(1 / 5)^{* *} \\
(1 / 2)^{* *} \\
1 \\
2 \\
3 \\
6 \\
12\end{array}$ & $\begin{array}{r}(1) \\
(2) \\
(4) \\
(5) \\
(6) \\
(7) \\
(9) \\
(11)\end{array}$ & $\begin{array}{l}\text { Concrete tank } \\
(295 \times 52 \times 38)\end{array}$ & $\begin{array}{l}\text { Anchovy larva } \\
\text { (fresh) }\end{array}$ \\
\hline Goldfish & $\begin{array}{l}6-1 \\
6-2 \\
6-3 \\
6-4 \\
6-5 \\
6-6 \\
6-7\end{array}$ & $\begin{array}{c}(1 / 2) * * \\
1 \\
3 \\
5 \\
6 \\
12 \\
\infty * * *\end{array}$ & $\begin{array}{c}(4) \\
(5) \\
(7) \\
(8) \\
(9) \\
(11) \\
-\end{array}$ & $\begin{array}{l}\text { Glass tank } \\
(60 \times 30 \times 25)\end{array}$ & $\begin{array}{l}\text { Tubifex } \\
\text { (alive) }\end{array}$ \\
\hline
\end{tabular}

* (1): 1200 in the 5th day. (2): 1200 in the 3 and 8 th days. (3): 1200 in the $2,4,6,8$, and 10 th days. (4): 1200 in the $1,3,5,7$, and 9 th days. (5): 1200 . (6): every 12 hours from 0600 to 1800 . (7): every 6 hours from 0600 to 1800 . (8): every 3 hours from 0600 to 1800 . (9): every 2 hours from 0600 to 1600 . (10): every 2 hours from 0400 to 1800 . (11): every 2 hours from 0000 to 2200 .

** $1 / 10,1 / 5$, and $1 / 2$ represent once in 10,5 , and 2 days respectively.

*** Fishes were fed in excess of their consumption throughout the experiment. 


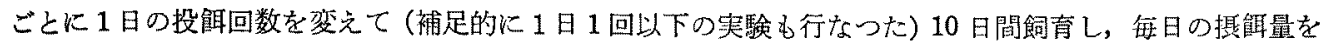
記録した。終かりに，実験型始の場合と同時間絶食させてから個体ごとに体重を測定した。

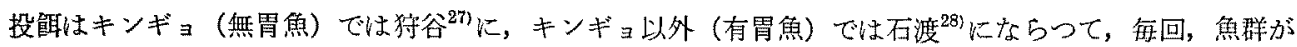

Table 2. Daily ration per fish in gram.

\begin{tabular}{|c|c|c|c|c|c|c|c|c|c|c|c|}
\hline \multirow{2}{*}{ Species of fish } & \multirow{2}{*}{$\begin{array}{l}\text { Exp. } \\
\text { No. }\end{array}$} & \multicolumn{10}{|c|}{ Day } \\
\hline & & 1 & 2 & 3 & 4 & 5 & 6 & 7 & 8 & 9 & 10 \\
\hline \multirow[t]{2}{*}{ Jack mackerel } & $\begin{array}{l}1-1 \\
1-2 \\
1-3 \\
1-4 \\
1-5\end{array}$ & $\begin{array}{l}-.33 \\
4.24 \\
5.75 \\
8.61\end{array}$ & $\begin{array}{l}\overrightarrow{2.03} \\
2.14 \\
7.94 \\
7.39\end{array}$ & $\begin{array}{l}4.46 \\
2.07 \\
2.19 \\
6.19 \\
5.23\end{array}$ & $\begin{array}{l}-\overline{3} \\
4.50 \\
4.84 \\
6.75\end{array}$ & $\begin{array}{l}3.58 \\
6.18 \\
5.29 \\
6.62\end{array}$ & $\begin{array}{l}-\overline{-} \\
3.94 \\
5.67 \\
5.14\end{array}$ & $\begin{array}{l}\overline{4.35} \\
6.90 \\
7.28 \\
8.90\end{array}$ & $\begin{array}{l}7.06 \\
3.51 \\
7.13 \\
4.81 \\
5.25\end{array}$ & $\begin{array}{l}-\overline{4.06} \\
7.06 \\
4.21 \\
4.16\end{array}$ & $\begin{array}{l}5.32 \\
5.76 \\
3.96 \\
5.45\end{array}$ \\
\hline & W.T.* & 19.4 & 19.9 & 19.3 & 19.2 & 19.6 & 19.4 & 19.1 & 19.4 & 18.8 & 17.4 \\
\hline \multirow[t]{2}{*}{ Goby } & $\begin{array}{l}2-1 \\
2-2 \\
2-3 \\
2-4 \\
2-5 \\
2-6\end{array}$ & $\begin{array}{l}\overline{-} \\
0.274 \\
0.442 \\
0.556 \\
0.496\end{array}$ & $\begin{array}{l}-\overline{-} \\
0.246 \\
0.070 \\
0.245 \\
0.139 \\
0.145\end{array}$ & $\begin{array}{l}0.303 \\
0.089 \\
0.105 \\
0.138 \\
0.135\end{array}$ & $\begin{array}{l}-\overline{3} \\
0.34 \\
0.139 \\
0.178 \\
0.206 \\
0.276\end{array}$ & $\begin{array}{c}-\overline{-} \\
0.129 \\
0.201 \\
0.206 \\
0.179\end{array}$ & $\begin{array}{l}-\overline{0} \\
0.304 \\
0.172 \\
0.201 \\
0.164 \\
0.212\end{array}$ & $\begin{array}{c}- \\
0.103 \\
0.164 \\
0.213 \\
0.267\end{array}$ & $\begin{array}{l}0.341 \\
0.350 \\
0.145 \\
0.193 \\
0.213 \\
0.197\end{array}$ & $\begin{array}{c}- \\
0.204 \\
0.065 \\
0.065 \\
0.149\end{array}$ & $\begin{array}{l}-\overline{0.208} \\
0.088 \\
0.273 \\
0.287 \\
0.257\end{array}$ \\
\hline & W.T.* & 19.7 & 20.1 & 19.8 & 19.7 & 19.9 & 19.7 & 19.4 & 19.8 & 19.5 & 17.8 \\
\hline \multirow[t]{2}{*}{ Rockfish } & $\begin{array}{l}3-1 \\
3-2 \\
3-3 \\
3-4 \\
3-5\end{array}$ & $\begin{array}{l}1 . \overline{15} \\
2.00 \\
2.23 \\
2.42\end{array}$ & $\begin{array}{l}1.08 \\
1.27 \\
2.17 \\
2.06 \\
1.97\end{array}$ & $\begin{array}{l}-\overline{1.34} \\
1.65 \\
1.53 \\
1.45\end{array}$ & $\begin{array}{l}1.21 \\
1.24 \\
1.60 \\
1.14 \\
1.17\end{array}$ & $\begin{array}{l}-\overline{1.28} \\
1.36 \\
1.30 \\
1.43\end{array}$ & $\begin{array}{l}1.51 \\
1.12 \\
1.93 \\
1.73 \\
1.51\end{array}$ & $\begin{array}{l}1 . \overline{0} \\
1.42 \\
1.43 \\
1.46\end{array}$ & $\begin{array}{l}1.41 \\
1.13 \\
1.74 \\
1.51 \\
1.49\end{array}$ & $\begin{array}{l}\overline{1.16} \\
1.48 \\
1.50 \\
1.80\end{array}$ & $\begin{array}{l}1.40 \\
1.02 \\
1.46 \\
1.31 \\
1.70\end{array}$ \\
\hline & W.T.* & 24.0 & 24.4 & 24.9 & 25.1 & 25.6 & 26.1 & 25.6 & 25.6 & 26.2 & 26.2 \\
\hline \multirow[t]{2}{*}{ Yakataisaki } & $\begin{array}{r}4-1 \\
4-2 \\
4-3 \\
4-4 \\
4-5\end{array}$ & $\begin{array}{l}0.044 \\
0.067 \\
0.063 \\
0.066 \\
0.071\end{array}$ & $\begin{array}{l}0.028 \\
0.041 \\
0.045 \\
0.050 \\
0.045\end{array}$ & $\begin{array}{l}0.031 \\
0.047 \\
0.049 \\
0.047 \\
0.041\end{array}$ & $\begin{array}{l}0.038 \\
0.050 \\
0.047 \\
0.051 \\
0.050\end{array}$ & $\begin{array}{l}0.036 \\
0.059 \\
0.060 \\
0.049 \\
0.052\end{array}$ & $\begin{array}{l}0.045 \\
0.048 \\
0.055 \\
0.049 \\
0.059\end{array}$ & $\begin{array}{l}0.048 \\
0.062 \\
0.059 \\
0.060 \\
0.059\end{array}$ & $\begin{array}{l}0.042 \\
0.063 \\
0.056 \\
0.059 \\
0.055\end{array}$ & $\begin{array}{l}0.054 \\
0.051 \\
0.059 \\
0.045 \\
0.057\end{array}$ & $\begin{array}{l}0.050 \\
0.050 \\
0.047 \\
0.047 \\
0.058\end{array}$ \\
\hline & W.T.* & 16.8 & 16.4 & 16.5 & 16.7 & 16.4 & 16.2 & 16.6 & 16.9 & 17.3 & 18.0 \\
\hline \multirow[t]{2}{*}{ Rainbow trout } & $\begin{array}{l}5-1 \\
5-2 \\
5-3 \\
5-4 \\
5-5 \\
5-6 \\
5-7 \\
5-8\end{array}$ & $\begin{array}{l}- \\
\overline{0} \\
0.82 \\
0.69 \\
0.99 \\
0.97 \\
1.33 \\
1.39\end{array}$ & $\begin{array}{l}- \\
\overline{-} \\
0 . \overline{59} \\
0.75 \\
0.97 \\
1.05 \\
1.08\end{array}$ & $\begin{array}{l}0.70 \\
0.84 \\
0.70 \\
0.76 \\
0.66 \\
1.02 \\
1.01\end{array}$ & $\begin{array}{l}\overline{-} \\
\overline{0} \\
0.82 \\
0.80 \\
0.64 \\
1.18 \\
1.02\end{array}$ & $\begin{array}{l}1.04 \\
0.81 \\
0.83 \\
0.76 \\
1.11 \\
0.96 \\
0.79\end{array}$ & $\begin{array}{c}\overline{-} \\
\overline{-} \\
0.95 \\
0.58 \\
0.80 \\
0.93 \\
0.91\end{array}$ & $\begin{array}{c}\overline{-} \\
1.07 \\
0.85 \\
1.02 \\
1.20 \\
1.02 \\
1.26\end{array}$ & $\begin{array}{l}0 . \overline{8} 9 \\
0.89 \\
1.27 \\
1.29 \\
1.46 \\
1.27\end{array}$ & $\begin{array}{c}- \\
0.91 \\
0.98 \\
0.97 \\
1.00 \\
1.08 \\
1.31\end{array}$ & $\begin{array}{c}\overline{-} \\
\overline{-} \\
1.03 \\
1.29 \\
1.31 \\
1.61 \\
1.54\end{array}$ \\
\hline & W.T.* & 12.5 & 12.7 & 12.5 & 12.4 & 12.4 & 12.4 & 12.7 & 12.5 & 12.7 & 12.5 \\
\hline \multirow[t]{2}{*}{ Goldfish } & $\begin{array}{l}6-1 \\
6-2 \\
6-3 \\
6-4 \\
6-5 \\
6-6 \\
6-7\end{array}$ & $\begin{array}{l}0.34 \\
0.33 \\
0.81 \\
0.91 \\
0.83 \\
1.54 \\
1.49\end{array}$ & $\begin{array}{l}-\overline{0} \\
1.06 \\
1.22 \\
1.63 \\
2.35 \\
2.18\end{array}$ & $\begin{array}{l}0.48 \\
0.42 \\
0.98 \\
1.24 \\
1.65 \\
2.77 \\
2.38\end{array}$ & $\begin{array}{l}0.34 \\
1.06 \\
1.56 \\
1.74 \\
2.55 \\
2.67\end{array}$ & $\begin{array}{l}0.36 \\
0.44 \\
1.12 \\
1.34 \\
2.30 \\
3.25 \\
2.49\end{array}$ & $\begin{array}{l}-\overline{0} \\
0.29 \\
1.18 \\
1.28 \\
1.73 \\
2.73 \\
2.17\end{array}$ & $\begin{array}{l}0.26 \\
0.26 \\
1.18 \\
1.38 \\
1.95 \\
3.24 \\
2.08\end{array}$ & $\begin{array}{l}-\overline{0} \\
0.23 \\
1.05 \\
1.13 \\
2.00 \\
2.17 \\
1.54\end{array}$ & $\begin{array}{l}0.32 \\
0.33 \\
1.30 \\
1.30 \\
1.73 \\
2.42 \\
2.02\end{array}$ & $\begin{array}{l}-\overline{3} \\
1.19 \\
1.30 \\
2.21 \\
2.75 \\
2.05\end{array}$ \\
\hline & W.T.* & 25.4 & 25.8 & 25.6 & 25.4 & 26.1 & 25.7 & 25.2 & 25.2 & 25.3 & 25.5 \\
\hline
\end{tabular}

* Mean water temperature, ${ }^{\circ} \mathrm{C}$. 
飽食する*まで行ない，一定容器中の投餌開始前と終了後の餌の重量の差を掟餌量とした。

実験に用いた魚種，投期回数とその時刻，およびその他の実験条件はT Table 1 に示したと扣りである。 な㧧，水温は每日午前 0 時，6時，正午，午後6 時にそれぞれ測定した。

\section{結果}

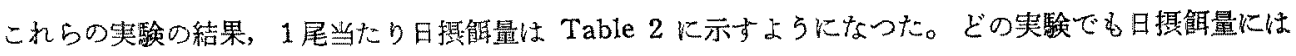
日間変動がある。特に, 第 1 日目の日摂飳量が多い傾向が見られ，また，マアジおよびニジマスの1日1回

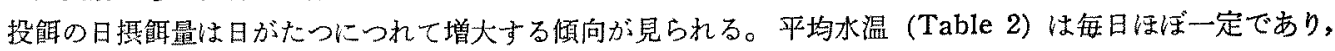
これと日損期量の間には関連が見られない。

次に，Table 2 に示した結果から，実験ごとに日摂餪率（日摄聑量の体重に対する割合）を計算すると Table 3 に示したよらになる。どの魚種でも日摆慨率は始如投慨回数とともに增加与るが，ある回数に達 するとるら增加しないことが放かる(Fig. 1)。

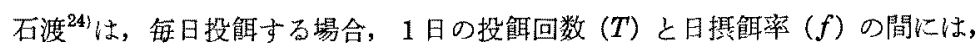

Table 3. Body weight, ration and daily rate of feeding.

\begin{tabular}{|c|c|c|c|c|c|c|c|c|c|c|c|c|}
\hline \multirow{2}{*}{$\begin{array}{l}\text { Species of } \\
\text { fish }\end{array}$} & \multirow{2}{*}{ Items } & \multicolumn{11}{|c|}{ Frequency of feeding per day } \\
\hline & & $(1 / 10)$ & $(1 / 5)$ & $(1 / 2)$ & 1 & 2 & 3 & 5 & 6 & 8 & 12 & $\infty$ \\
\hline $\begin{array}{l}\text { Jack } \\
\text { mackerel }\end{array}$ & $\begin{array}{l}W_{0} \\
W_{t} \\
F \\
f\end{array}$ & - & $\begin{array}{c}42.85 \\
43.56 \\
1.15 \\
0.027\end{array}$ & - & $\begin{array}{c}42.76 \\
47.00 \\
3.45 \\
0.077\end{array}$ & - & $\begin{array}{c}42.81 \\
49.43 \\
5.38 \\
0.117\end{array}$ & - & $\begin{array}{c}42.80 \\
49.56 \\
5.56 \\
0.120\end{array}$ & - & $\begin{array}{c}42.82 \\
51.13 \\
6.55 \\
0.139\end{array}$ & - \\
\hline Goby & $\begin{array}{l}W_{0} \\
W_{t} \\
F \\
f\end{array}$ & - & $\begin{array}{l}3.585 \\
3.633 \\
0.064 \\
0.018\end{array}$ & $\begin{array}{l}3.569 \\
4.033 \\
0.144 \\
0.038\end{array}$ & $\begin{array}{l}3.567 \\
3.888 \\
0.141 \\
0.038\end{array}$ & - & $\begin{array}{l}3.571 \\
4.285 \\
0.206 \\
0.053\end{array}$ & -- & $\begin{array}{l}3.593 \\
4.369 \\
0.218 \\
0.055\end{array}$ & - & $\begin{array}{l}3.582 \\
4.405 \\
0.231 \\
0.058\end{array}$ & - \\
\hline Rockfish & $\begin{array}{l}W_{0} \\
W_{t} \\
F \\
f\end{array}$ & - & - & $\begin{array}{c}13.60 \\
14.24 \\
0.66 \\
0.047\end{array}$ & $\begin{array}{c}13.62 \\
15.00 \\
1.17 \\
0.082\end{array}$ & - & $\begin{array}{c}13.57 \\
15.96 \\
1.68 \\
0.114\end{array}$ & $\begin{array}{c}13.63 \\
15.58 \\
1.57 \\
0.108\end{array}$ & - & $\begin{array}{c}13.60 \\
15.75 \\
1.64 \\
0.112\end{array}$ & - & - \\
\hline$\underset{\text { Ysaki }}{\text { Yakata }}$ & $\begin{array}{l}W_{0} \\
W_{t} \\
F \\
f\end{array}$ & - & - & $一$ & $\begin{array}{l}0.598 \\
0.660 \\
0.041 \\
0.066\end{array}$ & $\begin{array}{l}0.601 \\
0.715 \\
0.054 \\
0.082\end{array}$ & $\begin{array}{l}0.604 \\
0.706 \\
0.054 \\
0.082\end{array}$ & $\begin{array}{l}0.599 \\
0.697 \\
0.052 \\
0.080\end{array}$ & 一 & $\begin{array}{l}0.602 \\
0.714 \\
0.055 \\
0.083\end{array}$ & - & 一 \\
\hline $\begin{array}{l}\text { Rainbow } \\
\text { trout }\end{array}$ & $\begin{array}{l}W_{0} \\
W_{t} \\
F \\
f\end{array}$ & $\begin{array}{l}7.89 \\
7.58 \\
0.10 \\
0.013\end{array}$ & $\begin{array}{l}7.94 \\
7.78 \\
0.16 \\
0.020\end{array}$ & $\begin{array}{l}7.90 \\
8.72 \\
0.44 \\
0.053\end{array}$ & $\begin{array}{c}7.91 \\
10.39 \\
0.83 \\
0.091\end{array}$ & $\begin{array}{c}7.93 \\
10.62 \\
0.92 \\
0.099\end{array}$ & $\begin{array}{c}7.91 \\
10.99 \\
0.99 \\
0.105\end{array}$ & - & $\begin{array}{c}7.89 \\
11.27 \\
1.16 \\
0.121\end{array}$ & - & $\begin{array}{c}7.88 \\
11.32 \\
1.16 \\
0.121\end{array}$ & - \\
\hline Goldfish & $\begin{array}{l}W_{0} \\
W_{t} \\
F \\
f\end{array}$ & - & - & $\begin{array}{l}4.91 \\
4.75 \\
0.18 \\
0.036\end{array}$ & $\begin{array}{l}4.88 \\
5.01 \\
0.33 \\
0.067\end{array}$ & - & $\begin{array}{l}4.91 \\
6.84 \\
1.09 \\
0.186\end{array}$ & $\begin{array}{l}4.91 \\
6.98 \\
1.27 \\
0.213\end{array}$ & $\begin{array}{l}4.89 \\
7.98 \\
1.78 \\
0.276\end{array}$ & & $\begin{array}{l}4.92 \\
9.46 \\
2.58 \\
0.358\end{array}$ & $\begin{array}{l}4.95 \\
8.09 \\
2.11 \\
0.323\end{array}$ \\
\hline
\end{tabular}

$W_{0}$ : initial mean body weight $(\mathrm{g})$.

$W_{t}$ : final mean body weight $(\mathrm{g})$.

$F$ : ration per fish per day $(\mathrm{g})$.

$f$ : daily rate of feeding, $\left.F /\left(W_{0}+W_{t}\right) / 2\right\}$.

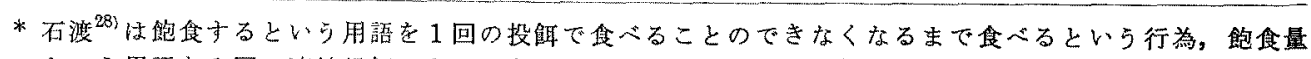

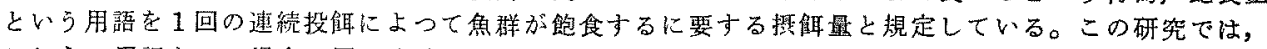
これらの用語をこの場合と同じ意味に用いる。 


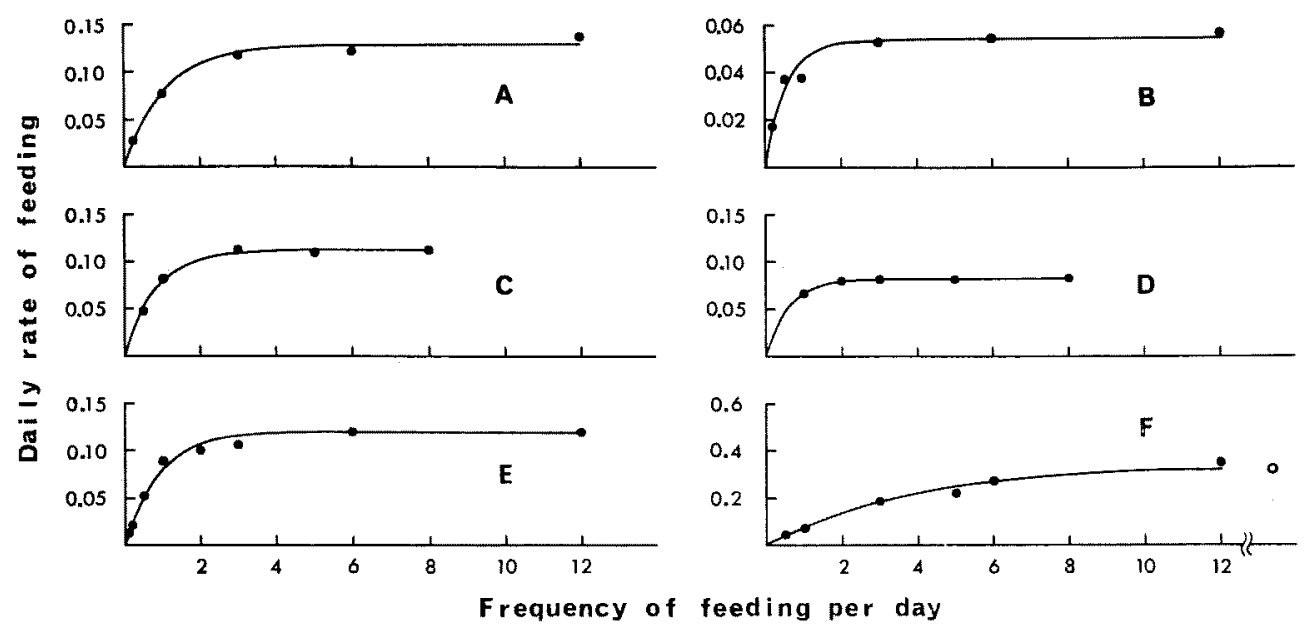

Fig. 1. Relationship between frequency of feeding per day and daily rate of feeding. A: jack mackerel, B: goby, C: rockfish, D: yalkataisaki, E: rainbow trout, F : goldfish.

Open circle: fish fed in excess of their consumption.

$$
f=C\left(1-e^{-m T}\right)
$$

の関係が成り立つことを認めている。ただし， $C$ 腚数 (日摂䬶率の極限但)， $m$ b定数である。ここでは， この $C$ を最大日掑触率と呼ぶ。また， $m$ は日掑慨率がての最大值に近づく速さを黄わしている。(1) 式を 先に得た結果に当てはめるため，DEMING ${ }^{29)}$ の方法を用いると，次のようになる。

$$
\begin{aligned}
& \checkmark \quad \text { ア ジ: } f=0.129\left(1-e^{-0.901 T}\right) \\
& \text { ド 口 メ: } f=0.054\left(1-e^{-1.815 T}\right) \\
& \rtimes \text { \& } ル: f=0.112\left(1-e^{-1.224 T}\right) \\
& \text { ヤカタイサキ: } f=0.082\left(1-e^{-1.660 T}\right) \\
& =シ \text { マ } \\
& \neq \text { ₹ } \neq: f=0.335\left(1-e^{-0.266 T}\right)
\end{aligned}
$$

計算曲線は害験値によく適合している(Fig. 1)。

いま， 1 日 1 回投餌 $(T=1)$ の飽食量を $R$, 体重を $W$ とすると， $f=R / W$ であるから，(1) 式から，

$$
m=-\log \left(1-\frac{R}{C W}\right)
$$

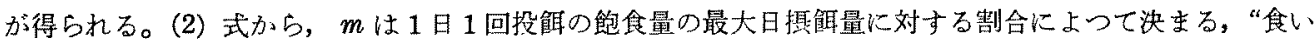
おき係数”とでも㭔ぶべき定数であることがわかる。

(1) 式から，各魚種について，日掑期率がその最大值の $95 \%$ になる投能回数を求めると，マアジでは 3.3 回，ドロメでは 1.7 回，メバルでは 2.4 回，ヤカタイサキでは 1.8 回，二ジマスでは 2.7 回，キン ギョでは 11.3 回となる。したがつて，日掑慨量はドロメ，ヤカタイサキでは 2 回，メバル，ニジマスでは

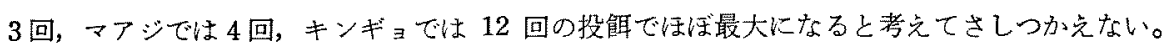

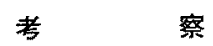

第1日目の日摂慨量が多い傾向が見られるのは，前日に䍃食しているためと考えられる。ぬた，マアジ拉 よびニジマスの1日1回投触の日摄铒量が増大寸る傾向が見られるのは，実験期間中の魚の生長によるむの と考えられる。乙かし，その他の場合やその他の魚種で，生長の速やかな場合にはこのような㑯向が見られ

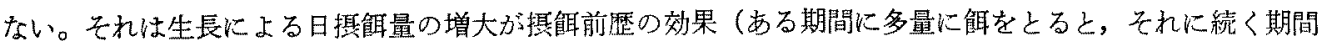
の摂槍量が低下する。この点については続報で述べる。によよつてうち消されたためであろう。 石渡 ${ }^{24)}$ はニジマスで $C=0.0672, m=1.0850$ を得た（平均体重: $5.8 \mathrm{~g}$, 平均水温: $11.8^{\circ} \mathrm{C}$, 慨：配合飼 
料)。著者らの結果は $C=0.120, m=1.100$ である（平均体重 $7.9 \mathrm{~g}$, 平均水温: $12.5^{\circ} \mathrm{C}$, 餌：カタクチイ ワシのシラス)。魚の大きさや水温はやや異なるが， $m$ の值は活ば一致している。この結果から見て飰の種 類の違いは $m$ にはほとんど影響しないと考兑られる。むた，Cの值には差があるが，これは魚の大きさ， 水温の違いから見て饃の释煩の遠いが最も効ていると思われる。

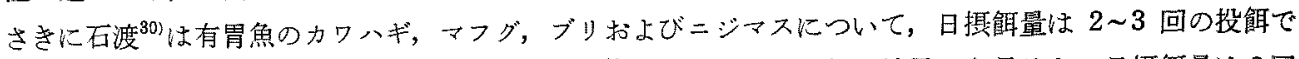

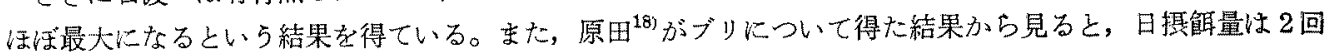

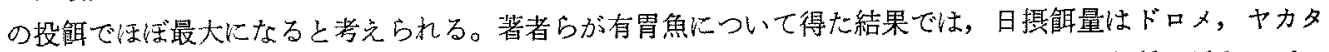

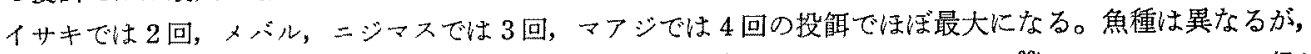
これらの結果はすべてほとんど一致している。一方, 特谷 ${ }^{311}$ がコイについて, 淈田 ${ }^{32)}$ がサンマについて得た 結果から見ると, これらの無胃魚では, 日摂慨量をその最大值に近つけるためには有胃魚の場合よりも多回 の投期が必要で亦万らと考光られる。著者らの得た結果では, 無胃魚のキンギョでは 12 回の投慨が必要で ある。このよらに然胃魚で多回の投慨が必要であるといらこと，いいかえれば食い扰き係数が小さいといら

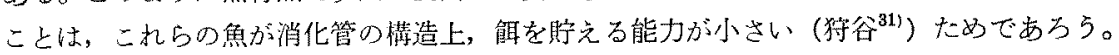

要約

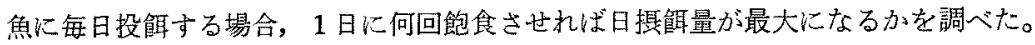

1） 1 日の投能回数 $(T)$ と日掑期率 $(f)$ の間には，先に報告されたよらに，

$$
f=C\left(1-e^{-m T}\right)
$$

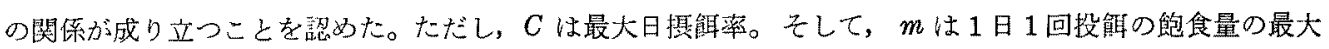

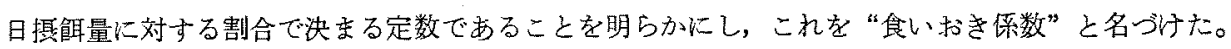

2) 日摂饋量はドロメ，ヤカタイサキでは 2 回，メバル，ニジマスでは 3 回，マアジでは 4 回，キンギョ では 12 回の投䭒でほぼ最大になる。

\section{文献}

1) B. DAWES: J. Mar. Biol. Ass. U.K., 17, 103 147 (1930).

2) B. DAwES: ibid., 17, $877 \sim 947$ (1931).

3) F. T. K. Pentelow: J. Exp. Biol., 16, $446 \sim 473$ (1939).

4) M. E. Brown: ibid., 22, 130 144 (1946).

5) M. Hatanaka and M. Takahashi: Tohoku J. Agr. Res., 7, $51 \sim 57$ (1956).

6) M. Hatanaka, M. KoSaKa, and Y. SATo: ibid., 7, 151 162 (1956).

7) M. Hatanaka, M. KosakA, and Y. Sato: ibid., 7, 163 174 (1956).

8) M. Hatanaka, K. Sekino, M. Takahashi, and T. Ichimura: ibid., 7, $351 \sim 368$ (1957).

9) M. Hatanaka and G. MURakawa: ibid., 9, $69 \sim 79$ (1958).

10）滈䍏正雄 - 烟中正吉：本誌，24，449 455（1958）.

11) M. Hatanaka and M. Takahashi: Tohoku J. Agr. Res., 11, 83 100 (1960).

12) M. Takahashi and M. HatanaKa: ibid. 11, $161 \sim 170$ (1960).

13) 畑中正吉 - 饭塚景記: 本誌, 28, 305 313 (1962).

14）袖中正吉 - 関野清成：本誌，28，949 954 (1962).

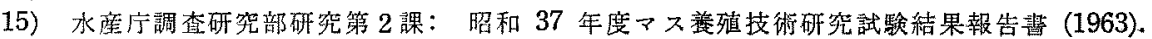

16) P. M. C. Davies: Comp. Biochem. Physiol., 12, $67 \sim 79$ (1964).

17) G. E. Davis and C. E. Warren: J. Wildl. Mgmt., 29, 846 871 (1965).

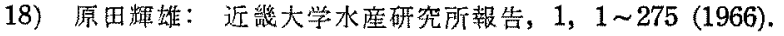

19) J. E. Palohermo and L. M. Dickie: J. Fish. Res. Bd. Canada, 23, 1209 1248 (1966).

20) H. Kawanabe: Mem. Coll. Sci., Univ. Kyoto, Series B, 33, 157 162 (1967).

21) T. J. Pandian: Mar. Biol., 1, 107 109 (1967).

22）跉木智之：日水研報告，17，33 43 (1967).

23）石渡直典・河野秀雄：水座增殖，16，47 52 (1968). 
24) 石渡㨁典：本誌, 35, 985 990 (1969).

25) 石渡直典：本誌，35，1049 1054 (1969).

26）吉田陽一：本誌, 36, 160 164 (1970).

27) 狩谷貞二: 水産增殖, 7, 29 36 (1960).

28) 石㴖值典：本誌，34，495 497 (1968).

29) W.E. DEMING：推計学によるデータのまとめ方, 森口繁一勍, 198 pp., 岩波㽬店, 東京 (1965).

30) 石渡直典：本誌, 35, 979 984 (1969).

31) 狩谷貞二: 水産堌殂, $4,1 \sim 8$ (1956).

32）堀田秀之：東北水研報告，11，47～64 (1958). 